\title{
CLIMA E TURISMO: UMA DISCUSSÃO NECESSÁRIA PARA MELHOR APROVEITAMENTO DOS ATRATIVOS TURÍSTICOS: CASO DE SÃO DOMINGOS, GO
}

\author{
Paulo Roberto Ferreira de Aguiar Junior ${ }^{1}$ \\ Juliana Ramalho Barros ${ }^{2}$ \\ Herika Silva Vasques ${ }^{3}$
}

Resumo: A atividade turística é atualmente uma fonte de renda indiscutível, meio a tantos segmentos que esta está envolvida. As viagens aumentam cada vez mais, entre os fatores pode-se citar os avanços técnicos-científicos e a melhora de indicadores econômicos. Contudo, alguns lugares recebem mais turistas que outros, isso pode estar ligado ao tipo de paisagem que é vendida, ou mesmo ao grau de profissionalização do trade turístico. Para além disso, há fatores que são determinantes para a escolha do destino. Esses elementos estão ligados aos aspectos físicosnaturais da localidades e entre eles está o clima. Nesse sentindo, o clima deve ser estudado para oferecer ao turista o melhor período de visitação. Também adequar as atividades turísticas as condições de chuva daquele período. Assim, o objetivo do artigo foi apresentar a discussão acerca de um dos elementos do clima; a precipitação, assim como entender a importância de seus tempos. Foi apresentado o caso de São Domingos, GO no bioma Cerrado.

Palavras-Chave: turismo, clima, precipitação, São Domingos

\section{CLIMATE AND TOURISM: A DISCUSSION REQUIRED FOR BETTER USE OF TOURIST ATTRACTIVES}

\begin{abstract}
Tourism is currently an undisputed source of income, among so many segments that it is involved. As travel increases more and more, technical and scientific advances and improved economic indicators can be cited. However, some places receive more tourists than others, which may be linked to the type of landscape that is sold, or even to the level of professionalization of tourism trade. In addition, there are factors that determine the choice of destination. These elements are linked to the physical aspects of the locality and among them is in the climate. In this sense, the climate must be studied to offer the tourist the best time to visit. Also suitable for tourist activities and rainy conditions during this period. Thus, the purpose of the article was presented in the discussion about one of the elements of climate; to include as well as understanding the importance of your times. The case of São Domingos, GO was presented in the Cerrado biome.
\end{abstract}

Keywords: tourism, climate, precipitation, Santo Domingo

\section{INTRODUÇÃO}

\footnotetext{
${ }^{1}$ Universidade Federal de Goiás - Instituto Socioeconomico.prf.geo@gmail.com

${ }^{2}$ Professora associada da Universidade Federal de Goiás. prf.geo@gmail.com

${ }^{3}$ Mestre (2017) em Geografia pela Universidade Federal de Goiás. Atualmente é professora - Colégio Estadual da Polícia Militar do Estado de Goiás - Hugo de Carvalho Ramos. prf.geo@gmail.com.
} 
O interesse por viagens não é recente, se pesquisarmos veremos registros desde a Grécia antiga, passando por Roma, entrando na Idade Média e assim por diante. No entanto, o motivo dessas viagens vem se transformando ao longo dos anos e, principalmente, a partir da Revolução Industrial. O avanço tecnológico e o advento do transporte de pessoas em massa possibilitou viagens mais longas e mudou a prática do turismo, tornando-o um fenômeno complexo e com muitas variáveis.

A discussão em torno do turismo não é simples, visto que esse fenômeno é um dos mais marcantes do mundo contemporâneo (BESANCENOT, 1990) e suas ações repercutem nos mais diversos sistemas, como: social, cultural, ambiental e econômico (BENI, 2001). O sistema econômico é talvez o mais presente nos discursos dos gestores, pois o turismo movimenta significativas somas em impostos e cria empregos, conforme aponta o último relatório da Organização Mundial de Turismo (UNWTO, 2015), segundo o qual a atividade turística gerou mais de US\$ 1,5 trilhão em receitas e movimentou mais de 1,184 milhão de pessoas, o que representa um aumento de $4,6 \%$ em relação ao ano anterior.

O turismo, como maior setor da economia global (SCOTT; MACBOYLE, 2001), tem, em seu planejamento, a peça-chave para o desenvolvimento desse setor. Para Trigo (1998), Beni (2001), Barreto (2003), Almeida (2006), Chavez e Pérez (2007), Oliveira (2008) e Llamas et al. (2012), é inevitável pensar em um destino turístico sem pensar no planejamento. Ainda mais, que seu crescimento não pode estar desassociado à proteção ambiental e cultural. Besancenot (1990) explica que não é por acaso que certos lugares possuem mais fluxo de turistas, fato derivado de um planejamento que para ele está ligado e alicerçado no clima. Barbiére (1981), Beson (1996), Scott e Macboyle (2001), Aranha e Festa (2014) e Fernandes (2017) também veem o clima como parte fundamental para a área de recreação e turismo.

Dessa forma, entender a sazonalidade do clima - "'tipos de tempos', são mais abrangentes, e se refere, justamente, às condições que se repetem, nem sempre são idênticas, porém produtoras de sensações fisiológicas semelhantes" (BARROS, 2009, p. 256) - é de suma importância para a atividade turística, uma vez que poderá levar a elaborar diferentes atividades para cada época do ano e a estabelecer o período ideal para a prática de algum segmento específico do turismo.

Neste trabalho, o arcabouço teórico da Geografia serve de base para nortear tais discussões, considerando, como Knafou et al. (1997) e Aranha e Guerra (2014), que a Geografia pode ser aplicada ao turismo e com ele contribuir, tendo o clima como um de seus pilares. Oliveira (2007) aponta que o turismo tem sido objeto de estudos da Geografia já há algum tempo e, segundo o autor, interessa a essa ciência uma visão de turismo enquanto fenômeno humano capaz de produzir e modificar espaços e criar ou alterar relações sociais.

Dessa forma, o respectivo trabalho tem por objetivo analisar a sazonalidade dos "tipos de tempos" no município de São Domingos (GO), localizado no nordeste goiano, na região geográfica intermediária. Espera-se, nesta pesquisa, apresentar alguns períodos de visitação mais propícios para usufruir da paisagem do bioma Cerrado e, por consequência, do Parque Estadual Terra Ronca.

\section{TURISMO E SUAS REPERCUSSÕES}


Durante milênios as pessoas viajaram por motivos distintos, a exemplo dos jogos - como na Grécia do século VIII a.C, quando os gregos viajavam para ver os jogos olímpicos - ou para fazer negócios no Mediterrâneo - os fenícios e as navegações (BARRETO, 2003). Se for feita uma pesquisa mais detalhada e extrapolar para o oriente, provavelmente encontrar-se-ão registros mais antigos ainda. Assim, é certo afirmar que as viagens sempre fizeram parte da vida humana.

O presente artigo, entretanto, está mais interessado no turismo moderno (século $X I X$ ) e contemporâneo (século $X X$ ). O foco no período moderno dá-se justamente porque foi no século XIX, após a Revolução Industrial (século XVIII), que começaram as primeiras viagens organizadas, utilizando a ferrovia como principal meio de transporte, haja vista ela ter capacidade maior para transportar grupos de viajantes. Nesse período também apareceu, pela primeira vez, a figura de um agente de viagem, Thomas Cook, o primeiro a se ocupar mais dos passageiros do que das cargas (BARRETO, 2003).

Além de todos os avanços tecnológicos que propiciaram o deslocamento em massa, houve também uma "revolução" no que se refere à ideia de tempo livre. Knouf et al. (1997) afirma ter havido uma profunda mudança social em relação ao tempo livre e que isso foi crucial para a prática do turismo: "le tourisme permet de saisir à la fois des aspects des deux mutations: l'industrielle et celle en cours" (KNOUF et al. 1997, p. 195).

Destarte, ao entender que o desenvolvimento do turismo está atrelado aos avanços tecnológicos e à concepção de lazer, será usado todo o arcabouço teórico da ciência geográfica para discutir o tema, visto que a atividade turística se manifesta no espaço, uma das preocupações centrais da Geografia.

O turismo manifesta-se no espaço, entendido como "um conjunto indissociável, solidário e também contraditório, de sistemas de objetos e sistemas de ações, não considerados isoladamente, mas como o quadro único no qual a história se dá" (SANTOS, 1996, p. 63). Por entender que esse conceito caminha junto com o turismo - visto ser este um sistema complexo que produz e, ao mesmo tempo, é capaz de amenizar impactos e efeitos negativos para a localidade onde se desenvolve -, o turista se torna um agente ativo na transformação do espaço (AGUIAR, 2019).

Para além dos estudos do espaço tem-se as mais diversas áreas atuando concomitantemente para o melhor planejamento turístico de uma localidade. Temos a Cartografia, como afirma Oliveira (2007), de grande importância para o planejamento da atividade turística, assim como a geomorfologia. Para Aranha e Guerra (2014), o trabalho é fundamental para minimizar os impactos e efeitos negativos do turismo sobre a paisagem natural. A ciência geográfica, com todos os seus campos de conhecimento, ajuda a consolidar os estudos acerca do turismo e, com isso, o torna cada vez mais eficaz em seu desenvolvimento.

Outro campo da Geografia que se atém aos estudos do turismo, como já citado, é a Climatologia, mais especificamente a Climatologia Geográfica, cujas bases surgem a partir das premissas propostas por Max Sorre (1951, p. 13-14), segundo o qual o clima "é o ambiente atmosférico constituído pela série de estados atmosféricos acima de um dado lugar em sua sucessão habitual" (tradução nossa). Partindo dessa assertiva, a Climatologia Geografia investiga não apenas a combinação dos elementos atmosféricos, mas a sucessão habitual dos tipos de tempo, bem como as excepcionalidades do chamado ritmo climático, e interessa-se, ainda, pela maneira como o comportamento da atmosfera pode influenciar ou repercutir sobre as atividades humanas. 
Entendendo que o clima é um dos elementos fundamentais para estabelecer estratégicas de planejamento e consolidação do turismo, como afirmam Barbiére (1981), Beson (1996), Martins (1999) e Scott e Macboyle, (2001), será apresentada uma discussão acerca do clima para o município de São Domingos, Goiás, pois essa área possui alguns atrativos turísticos que merecem atenção por ter potencial para se tornar um polo de atração regional e quiçá nacional do ecoturismo (FERREIRA, 2019).

\section{CLIMA E TURISMO EM SÃO DOMINGOS, GOIÁS}

O município de São Domingos localiza-se no nordeste do estado de Goiás, conforme Figura 1, e faz parte das Regiões Geográficas Intermediárias. No último levantamento censitário (IBGE, 2010), o município contava com uma população de 11.272 habitantes, distribuídos em uma unidade territorial de $3.295,74 \mathrm{~km}^{2}$, o que lhe conferia uma densidade demográfica de $3,42 \mathrm{hab} . / \mathrm{km}^{2}$. De acordo com o IBGE (2018), em 2017, a população foi estimada em 12.585 habitantes. O Produto Interno Bruto (PIB) per capita foi, em 2015, de R $\$ 11.039,66$, ocupando a $229^{a}$ posição no ranking dos municípios do estado, com Índice de Desenvolvimento Humano (IDH) (2010) de 0,597, classificado como baixo desenvolvimento humano, inclusive ocupando a penúltima posição na classificação dos municípios goianos. Para efeito de comparação, a capital, Goiânia, a primeira colocada dos 246 municípios do estado de Goiás, apresenta índice de 0,799 (PNUD, 2018).

Figura 1: Município de São Domingos-GO

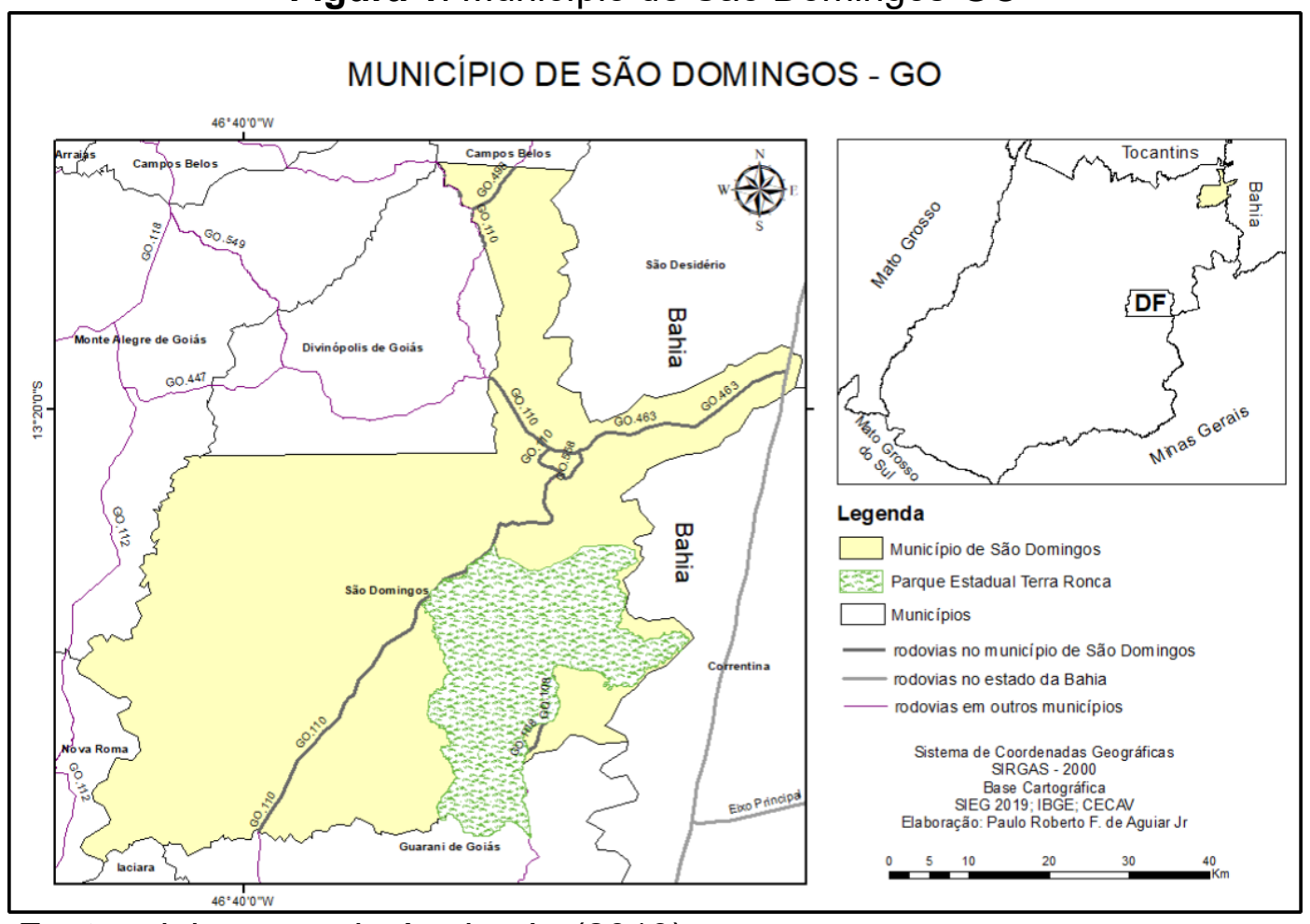

Fonte: elaboração de Aguiar Jr. (2019). 
O PIB desse município demonstra uma distribuição relativamente equilibrada entre os setores da agropecuária, indústria e serviços, como pode ser percebido na Tabela 1.

Tabela 1: PIB per capita do município de São Domingos

\begin{tabular}{lc}
\multicolumn{1}{c}{ Atividade econômica } & $\mathrm{R} \$$ \\
\hline Agropecuária & 32.004 .840 \\
Indústria & 28.846 .840 \\
Serviços - Exclusiva Administração, Defesa, Educação e Saúde & 34.455 .160 \\
Públicas e Seguridade Social & \\
\hline
\end{tabular}

Fonte: IBGE (2017).

O município, como já dito, apresenta os piores indicadores socioeconômicos do estado de Goiás e tampouco tem um quadro institucional que aja de forma ativa na elaboração de projetos e ações que visem o desenvolvimento e o seu crescimento econômico. Conforme Barreira (2002, p. 28), a região onde se insere São Domingos está "vinculada à ideia de ser o 'corredor da miséria' de Goiás".

Diante de um cenário desfavorável no município em relação aos indicadores socioeconômicos, vê-se no turismo uma alternativa ao crescimento econômico, visto que essa área possui inúmeros atrativos voltados ao ecoturismo, entre eles as cavernas localizadas no Parque Estadual Terra Ronca (PETeR) (Figura 2)

Figura 2: Parque Estadual Terra Ronca-GO

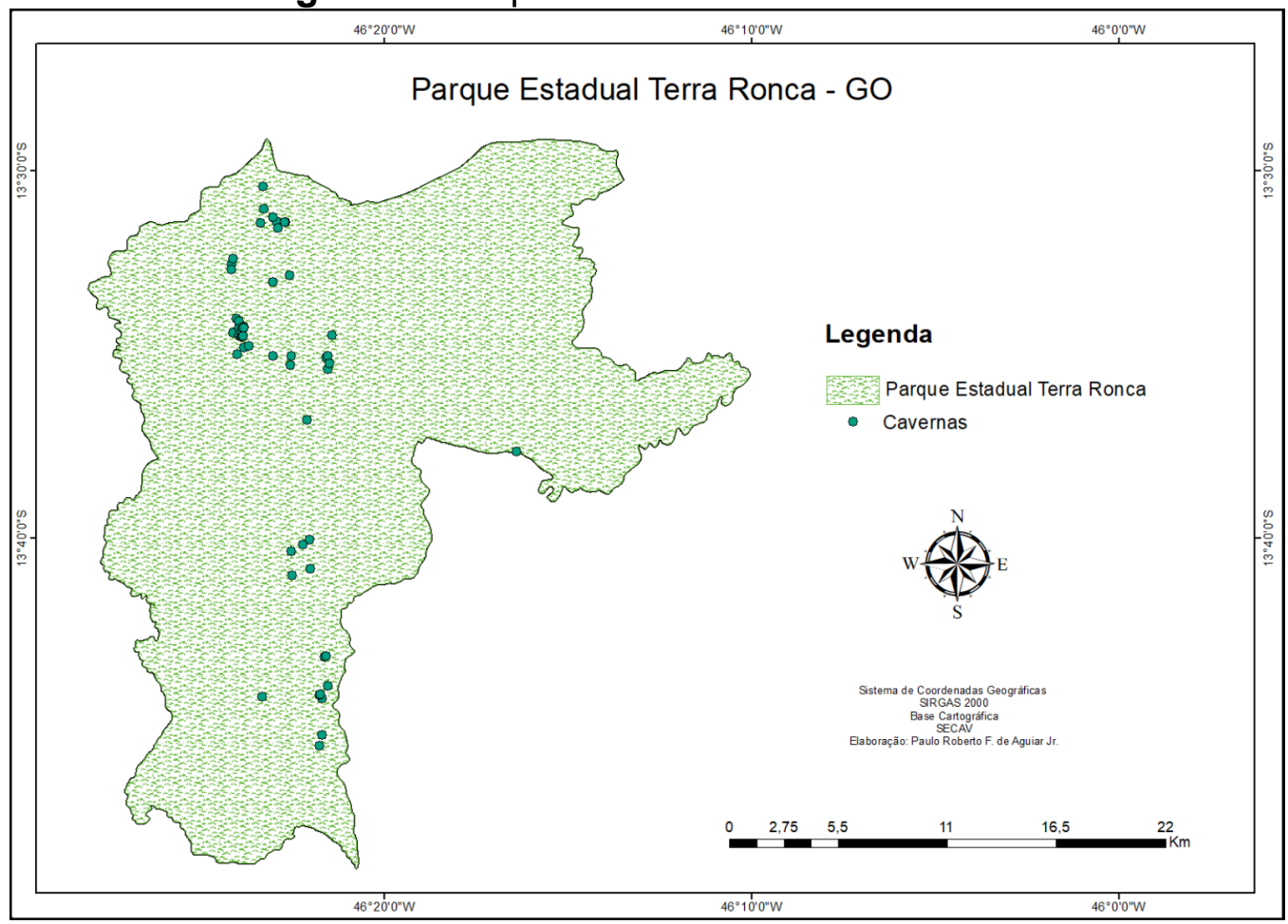

Fonte: elaboração de Aguiar Jr. (2019). 
Figura 3: Fotos das cavernas Angélica e Terra Ronca I
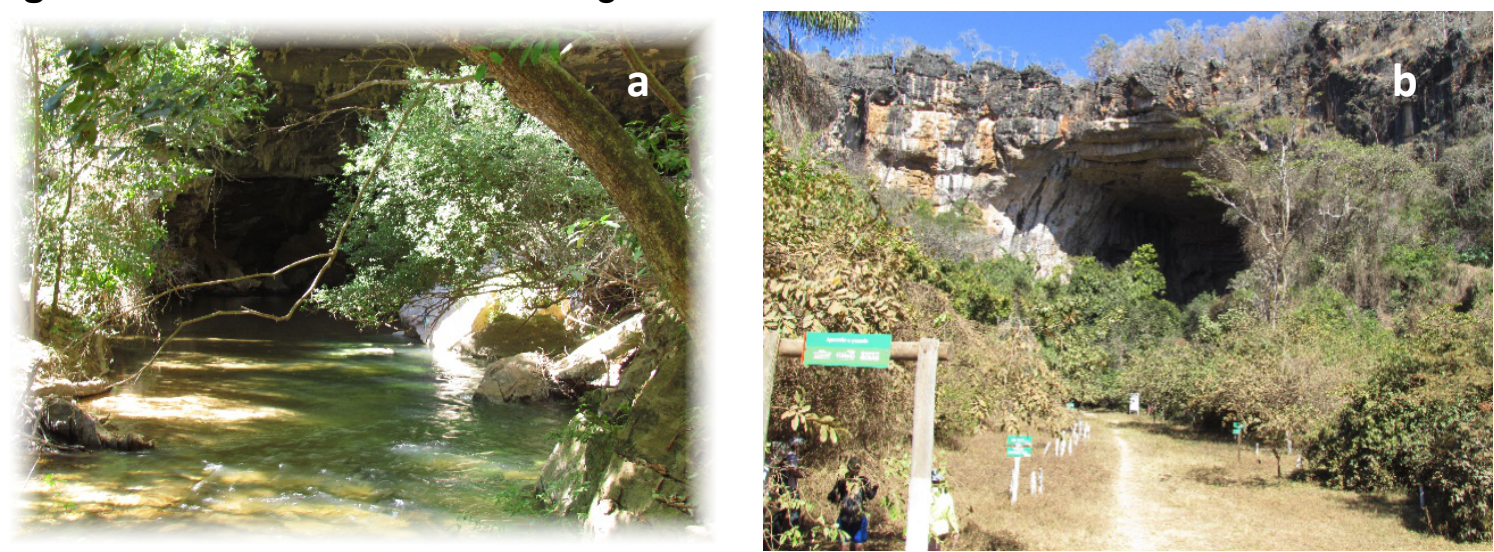

Fotos: Aguiar (2018). a) Caverna Angélica b) Caverna Terra Ronca I. Ambas estão localizadas no Parque Estadual Terra Ronca, no município de São Domingos-GO.

As cavernas mostradas na Figura 3 fazem parte do complexo de cavernas que fica no Parque Estadual Terra Ronca (PETeR), criado pela Lei n. 10.879, de julho de 1989, e ainda não possui plano de manejo, que visa

[...] levar a Unidade de Conservação a cumprir com os objetivos estabelecidos na sua criação; definir objetivos específicos de manejo, orientando a gestão da Unidade de Conservação; promover o manejo da Unidade de Conservação, orientado pelo conhecimento disponível e/ou gerado. (BRASIL, 2018).

O parque, além de ser um dos principais complexos espeleológicos da América Latina, também foi declarado Reserva da Biosfera pela Unesco em 2000. Esse complexo de cavernas atrai turistas e aventureiros de toda parte do mundo, curiosos para conhecer as belezas naturais, rios de águas cristalinas que formam salões internos, formações de estalactites e estalagmites, helictites, colunas, flores de pedras, entre outras formações. As cavernas mais conhecidas e visitadas são as já anteriormente apresentadas: Terra Ronca I e Angélica.

Além do complexo cavernícola que o município possui há outras belezas naturais capazes de atrair turistas de todas as partes, como as veredas, vistas na Figura 4. 
Figura 4: Veredas no município de São Domingos-GO

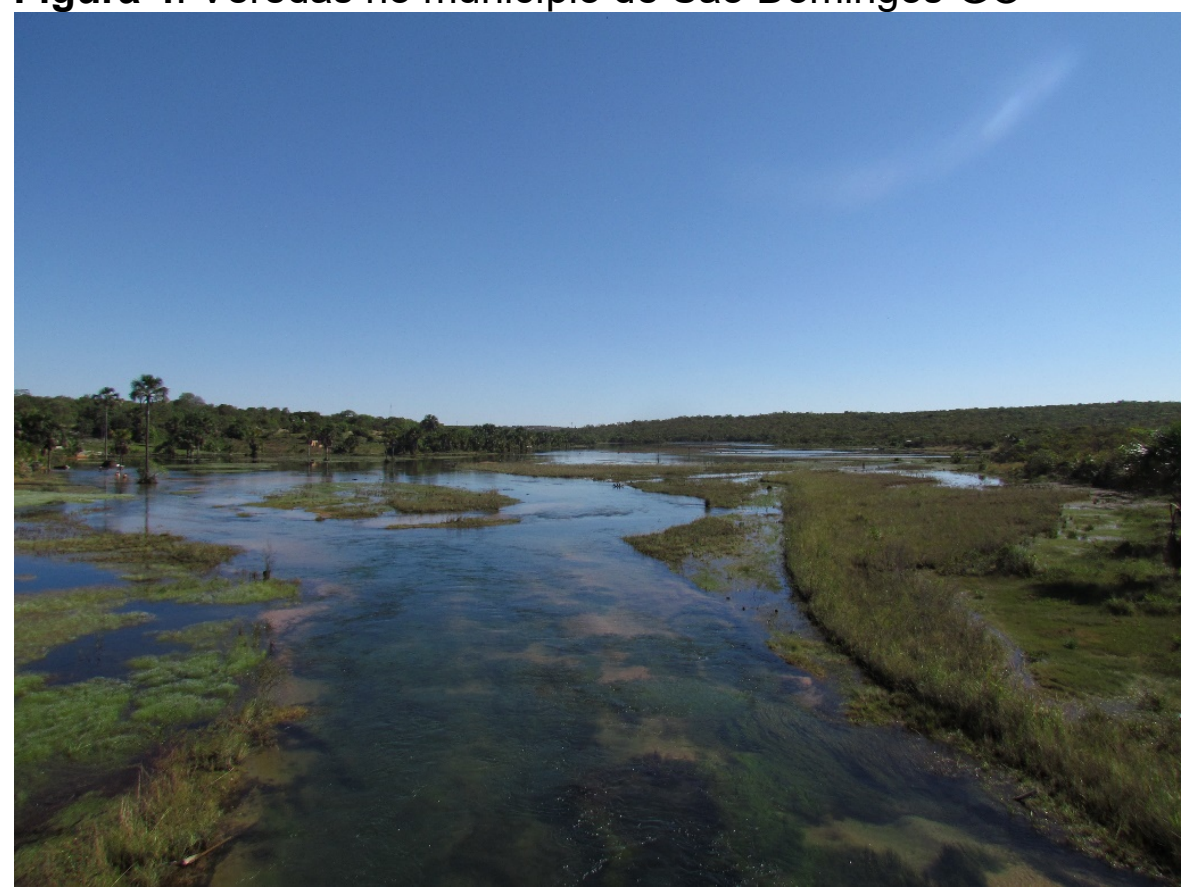

Foto: Aguiar (2018).

Assim, os atrativos voltados para o fomento do ecoturismo estão presentes por toda a parte no município, inclusive as geoformas espetaculares que encontramos para onde quer que olhemos.

As variações sazonais podem e influenciam a tomada de decisão para visitação de núcleos como o município de São Domingos (GO), pois para além das belezas naturais apresentadas anteriormente o clima na região em determinados períodos do ano inviabiliza determinadas práticas do ecoturismo. Dessa forma, Besancenot (1990) afirma que há pouca dúvida de que a sazonalidade do clima é responsável pelo fenômeno turístico. O mesmo autor trabalhou com indicadores que possibilitam realizar um planejamento para a área, entretanto, optamos por fazer uma análise rítmica na região para apontar o ótimo de visitação no município. Para isso, apresentaremos o clima da região Centro-Oeste para, assim, analisar o recorte espacial proposto, São Domingos (GO).

\section{CLIMA NO CENTRO-OESTE}

Para entender melhor as variações sazonais climáticas no município de São Domingos (GO) é necessário entender o contexto regional no qual o município se insere. Barros (2003) afirma que a massa Tropical Atlântica (Ta) frequentemente domina a região Centro-Oeste. A justificativa para tal afirmação é "devido à ação persistente do anticiclone semifixo do Atlântico Sul, tem uma atuação bastante relevante durante o ano todo" (BARROS, 2003, p. 95).

Além da Ta há a massa Equatorial Continental (EC), originária da planície amazônica, que tende a avançar de NW ora para SE, ora para Esse, atingindo a região Centro-Oeste e provocando elevação das temperaturas. Ademais, é responsável pelo aumento da umidade e das precipitações. 
Acerca da região Centro-Oeste, Nimer (1979, p.393) apud Barros (2003, p 98) traz as seguinte considerações:

\begin{abstract}
Embora a Região Centro-Oeste não possua áreas serranas, a oposição entre suas vastas superfícies baixas (menos de $200 \mathrm{~m}$ ), as extensas chapadas sedimentares (entre 700 a $900 \mathrm{~m}$ ) e as elevadas superfícies cristalinas (de 900 a mais de 1200 m de altitude) somadas a uma extensão latitudinal que suplanta a das demais regiões brasileiras (entre 5 e $22^{\circ}$ lat. Sul), confere-lhe uma diversificação térmica ao longo do seu território, somente superada pela que se verifica na Região Sudeste do Brasil. Enquanto estes dois fatores geográficos (relevo e latitude) levam à diversificação térmica, o mecanismo atmosférico, determinando uma marcha estacional de precipitação pluviométrica semelhante (máximo no verão e mínimo no inverno) atua no sentido de criar uma uniformidade regional. Portanto, na Região Centro-Oeste, o mecanismo atmosférico (fator dinâmico) constitui o fator regional que assegura uma certa homogeneidade climática, enquanto que o relevo, através da variação da altitude e a variação latitudinal, leva à heterogeneidade.
\end{abstract}

A descrição do clima para a região Centro-Oeste se estende para o município de São Domingos (GO), que possui um clima tropical semiúmido, conhecido também por clima de savana, bem como duas estações bem definidas: a da seca (outono/inverno) e a chuvosa (primavera/verão). No período do verão ocorrem, frequentemente, veranicos, que representam vários dias consecutivos sem chuva no período chuvoso, além disso, a região é eventualmente atingida pela massa de ar polar, que provoca quedas acentuadas nas temperaturas (BARREIRA, 2002).

Como apresentado por Nimer (1979), fatores geográficos como o relevo e a latitude influenciam na diversificação térmica, enquanto as características de regime de chuvas na região Centro-Oeste se devem quase exclusivamente aos sistemas atmosféricos, atribuindo à topografia a distribuição da precipitação ao longo do espaço geográfico da região. "A temperatura e a precipitação pluviométrica são os principais elementos atmosféricos que definem o clima da região Centro-Oeste" (VASQUES, 2017, p. 46).

Uma análise com base no Pluviograma de Schröder (Figuras 4 e 5) - estação meteorológica de Posse (OMM: 83332), Instituto Nacional de Meteorologia (Inmet) e da Agência Nacional de Águas (Ana) de São Domingos 01346000, do período de 01/01/2008 a 01/01/2018, nos mostra, por meio de dados, o que Nimer (1979), Barreira (2002) e Barros (2003) apresentam: um inverno seco e um verão chuvoso.

Figura 5: Pluviograma de Schröder - Estação São Domingos (Ana)

\begin{tabular}{|c|c|c|c|c|c|c|c|c|}
\hline & Jan & Fev & Mar & Abr & Mai & Jun & Jul & Ago \\
\hline 2008 & $10,97 \%$ & $17,99 \%$ & $14,72 \%$ & $10,43 \%$ & $0,00 \%$ & $0,00 \%$ & $0,00 \%$ & $0,00 \%$ \\
\hline 2009 & $12,66 \%$ & $11,82 \%$ & $6,96 \%$ & $20,92 \%$ & $3,90 \%$ & $1,07 \%$ & $0,00 \%$ & $0,92 \%$ \\
\hline 2010 & $17,95 \%$ & $8,58 \%$ & $19,66 \%$ & $4,90 \%$ & $1,77 \%$ & $0,00 \%$ & $0,00 \%$ & $0,00 \%$ \\
\hline 2011 & $10,08 \%$ & $13,64 \%$ & $14,30 \%$ & $9,04 \%$ & $0,02 \%$ & $0,00 \%$ & $0,00 \%$ & $0,00 \%$ \\
\hline 2012 & $16,32 \%$ & $10,26 \%$ & $9,91 \%$ & $1,26 \%$ & $0,00 \%$ & $0,00 \%$ & $0,00 \%$ & $0,00 \%$ \\
\hline 2013 & $21,37 \%$ & $6,33 \%$ & $10,34 \%$ & $19,41 \%$ & $0,39 \%$ & $0,13 \%$ & $0,00 \%$ & $0,00 \%$ \\
\hline 2014 & $15,88 \%$ & $10,59 \%$ & $21,90 \%$ & $4,74 \%$ & $1,11 \%$ & $0,00 \%$ & $0,28 \%$ & $0,00 \%$ \\
\hline 2015 & $5,29 \%$ & $11,64 \%$ & $31,74 \%$ & $15,83 \%$ & $6,55 \%$ & $0,00 \%$ & $0,00 \%$ & $0,00 \%$ \\
\hline 2016 & $31,47 \%$ & $4,90 \%$ & $18,66 \%$ & $1,37 \%$ & $0,00 \%$ & $0,08 \%$ & $0,00 \%$ & $0,00 \%$ \\
\hline 2017 & $9,99 \%$ & $19,70 \%$ & $8,01 \%$ & $19,53 \%$ & $5,79 \%$ & $0,00 \%$ & $0,00 \%$ & $0,00 \%$ \\
\hline 2018 & $4,80 \%$ & $13,83 \%$ & $20,56 \%$ & $11,75 \%$ & $0,00 \%$ & $0,00 \%$ & $0,00 \%$ & $0,94 \%$ \\
\hline
\end{tabular}


Figura 6: Pluviograma de Schröder - Estação Posse (Inmet)

\begin{tabular}{|r|rrrr|r|r|r|r|r|r|r|r|r|r|}
\hline 2008 & $12,90 \%$ & $12,77 \%$ & $17,54 \%$ & $10,50 \%$ & $0,38 \%$ & $0,00 \%$ & $0,00 \%$ & $0,00 \%$ & $1,75 \%$ & $2,11 \%$ & $23,15 \%$ & $18,91 \%$ \\
2009 & $10,03 \%$ & $9,78 \%$ & $9,54 \%$ & $14,44 \%$ & $5,27 \%$ & $0,13 \%$ & $0,00 \%$ & $1,04 \%$ & $2,33 \%$ & $15,08 \%$ & $12,99 \%$ & $19,37 \%$ \\
2010 & $10,67 \%$ & $6,92 \%$ & $17,32 \%$ & $4,67 \%$ & $5,46 \%$ & $0,00 \%$ & $0,00 \%$ & $0,00 \%$ & $2,14 \%$ & $12,05 \%$ & $18,42 \%$ & $22,36 \%$ \\
2011 & $22,82 \%$ & $8,58 \%$ & $15,64 \%$ & $7,11 \%$ & $0,95 \%$ & $0,00 \%$ & $0,00 \%$ & $0,00 \%$ & $0,00 \%$ & $12,82 \%$ & $12,29 \%$ & $19,79 \%$ \\
2012 & $32,21 \%$ & $9,14 \%$ & $6,09 \%$ & $3,44 \%$ & $1,70 \%$ & $0,00 \%$ & $0,00 \%$ & $0,00 \%$ & $0,55 \%$ & $1,17 \%$ & $32,73 \%$ & $12,96 \%$ \\
2013 & $20,61 \%$ & $5,47 \%$ & $20,51 \%$ & $14,47 \%$ & $0,83 \%$ & $0,79 \%$ & $0,00 \%$ & $0,00 \%$ & $0,72 \%$ & $3,71 \%$ & $10,67 \%$ & $22,22 \%$ \\
2014 & $11,70 \%$ & $9,33 \%$ & $23,35 \%$ & $10,04 \%$ & $5,15 \%$ & $0,00 \%$ & $0,00 \%$ & $0,00 \%$ & $0,08 \%$ & $9,10 \%$ & $15,49 \%$ & $15,75 \%$ \\
2015 & $5,30 \%$ & $5,70 \%$ & $15,41 \%$ & $23,09 \%$ & $5,49 \%$ & $0,00 \%$ & $0,04 \%$ & $0,00 \%$ & $0,02 \%$ & $7,62 \%$ & $28,95 \%$ & $8,39 \%$ \\
2016 & $31,37 \%$ & $8,18 \%$ & $16,34 \%$ & $0,69 \%$ & $0,00 \%$ & $0,60 \%$ & $0,00 \%$ & $1,04 \%$ & $2,39 \%$ & $5,40 \%$ & $13,94 \%$ & $20,04 \%$ \\
2017 & $11,32 \%$ & $17,91 \%$ & $17,03 \%$ & $7,06 \%$ & $3,38 \%$ & $0,00 \%$ & $0,00 \%$ & $0,00 \%$ & $0,00 \%$ & $1,06 \%$ & $18,13 \%$ & $24,10 \%$ \\
2018 & $10,88 \%$ & $15,78 \%$ & $12,72 \%$ & $13,87 \%$ & $0,00 \%$ & $0,00 \%$ & $0,00 \%$ & $3,52 \%$ & $0,32 \%$ & $8,01 \%$ & $19,54 \%$ & $15,37 \%$ \\
\hline
\end{tabular}

Legenda

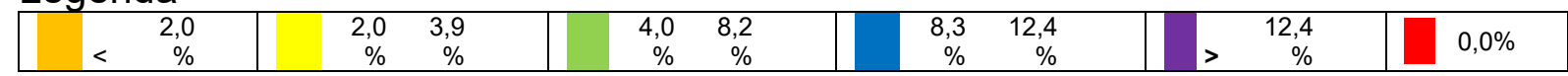

Fonte: elaborada por Hérika (2019).

A partir da distribuição temporal da precipitação, pode-se começar a pensar no seguimento do turismo a ser praticado no município, levando em consideração apenas as condições pluviométricas. Dessa forma, foi selecionado, conforme quadro a seguir, alguns seguimentos do turismo que mostram que o clima, em especial as precipitações, interferem diretamente em sua prática.

Quadro 1: Turismo com base na Natureza

\begin{tabular}{|l|l|}
\hline $\begin{array}{l}\text { Paisagís- } \\
\text { tico }\end{array}$ & $\begin{array}{l}\text { Refere-se à demanda por núcleos receptores cujo principal produto } \\
\text { turístico é a paisagem, os aspectos cênicos da natureza, } \\
\text { compreendendo-se aí todos aqueles locais em que característica } \\
\text { geográficas, ecológicas e mesológicas, combinadas, constituem o } \\
\text { principal fator de atração. }\end{array}$ \\
\hline Aventura & $\begin{array}{l}\text { Denominação dada ao deslocamento de pessoas para espaços } \\
\text { naturais, com ou sem roteiros programados e ausência ou incipiência } \\
\text { de equipamentos receptivos, motivados pela atração exercida pelo } \\
\text { desconhecido e desejo de enfrentar situações de desafio físico e } \\
\text { emocional. Compreende múltiplas formas de treinamento de } \\
\text { sobrevivência na selva e em outros locais inóspitos ou ainda não } \\
\text { desbravados e contato com culturas primitivas. }\end{array}$ \\
\hline
\end{tabular}

(continua) 


\begin{tabular}{|l|l|}
\hline Ecológico & $\begin{array}{l}\text { (conclusão) } \\
\text { Denominação dada ao deslocamento de pessoas para espaços } \\
\text { naturais, com ou sem equipamentos receptivos, motivadas pelo } \\
\text { desejo/necessidade de fruição da natureza, observação passiva da } \\
\text { flora, fauna, da paisagem e dos aspectos cênicos em torno. Nesse } \\
\text { sentido, pode ser também chamado de turismo de natureza, turismo } \\
\text { verde. Incluem-se aqui também aquelas que buscam observações } \\
\text { participante e interativa com o meio natural, na prática de longas } \\
\text { caminhadas, escalada, desbravamento e abertura de trilhas, rafting e } \\
\text { outros esportes radicais em que a natureza é apenas o pano de fundo } \\
\text { para o desafio de superar limites físicos de tolerância como canyoning } \\
\text { e off-road. Somam-se a essas atividades o exercício eventual da caça } \\
\text { e da pesca, excursões programadas para pontos geográficos de } \\
\text { interesse turístico: rios, montanhas e chapadas, grutas e cavernas, } \\
\text { minas e jazidas. }\end{array}$ \\
\hline $\begin{array}{l}\text { Ecoturis- } \\
\text { mo } \\
\text { protegidos pelo estado ou controlados em parceria com associações } \\
\text { locais e ONGs. Pressupõe sempre uma utilização controlada da área } \\
\text { com planejamento de uso sustentável de seus recursos naturais e } \\
\text { culturais, por meio de estudos de impacto ambiental, estimativa da } \\
\text { capacidade de carga e suporte do local, monitoramento e avaliação } \\
\text { constantes, com plano de manejo e sistema de gestão responsável. }\end{array}$ \\
\hline
\end{tabular}

Fonte: Beni (2001).

\section{METODOLOGIA}

A elaboração da respectiva pesquisa exigiu uma busca bibliográfica acerca do tema Clima e Turismo, que, por meio desta, chegou-se a nomes importantes como Beson (1990, 1996), Scott e Macboyle (2001), bem como autores nacionais como Barbiére (1981) e Aranha e Festa (2014), por meio dos quais foi possível mediar um diálogo sobre a importância do estudo do clima para o turismo. Para as discussões acerca do clima, e, principalmente, o clima da região Centro-Oeste, foi usado Barros (2003) e Vasques (2017).

As exposições sobre o turismo foram feitas a partir de Beni (2001), Barreto (2003) e Ferreira (2019), pesquisadores sobre turismo utilizados neste artigo em busca de uma visão qualitativa, além dos outros autores estudiosos de clima e turismo. Para além das discussões qualitativas, Schröder (1956) mostra a variação porcentual das chuvas ao longo dos meses do ano, o que possibilitou ver a distribuição anual para, assim, realizar a análise sobre os melhores períodos para visitação e, por conseguinte, qual seguimento do turismo para esse período. Os dados para a utilização do Pluviograma de Schröder foram retirados da estação meteorológica de Posse (OMM: 83332), BDMEP - Inmet e da Agência Nacional de Águas (Ana) de São Domingos 01346000, durante o período de 01/01/2008 a 01/01/2018. A análise de uma série de 10 anos permitiu visualizar que não houve mudanças drásticas em relação à precipitação. Viu-se a necessidade de coletar dados da estação de Posse para comparar os dados da estação de São Domingos, sendo importante coletar dados de outas estações, apesar de esta ser a mais próxima do município $\cong 143 \mathrm{~km}$. 
Todas as análises sobre Clima e Turismo foram feitas no município de São Domingos, Goiás. Para representá-lo, foram utilizados produtos georreferenciados do banco de dados do Sistema Estadual de Geoinformação (Sieg) e do Centro Nacional de Pesquisa e Conservação de Cavernas (Cecav). Todos os dados foram tratados em GIS no ArcMap 10.1.

Dessa forma, a metodologia utilizada é a qualitativa-quantitativa, visto entender-se que somente a utilização de uma ou outra traria uma visita restrita para entender o tema. Além das leituras sobre o tema e da análise dos dados coletados foi também necessário fazer duas visitas in loco, o que possibilitou perceber as diferenças da paisagem, já que as visitas foram realizadas em períodos diferentes.

\section{RESULTADOS}

Com base nos dados levantados por meio do Pluviograma de Schröder de 2008 a 2018, uma série de 10 anos, foi possível visualizar que não houve drásticas alterações na distribuição temporal das chuvas em São Domingos. Comparando com as precipitações em Posse, município que também serviu para coleta de dados acerca das precipitações, viu-se que há certa regularidade nas precipitações e secas, com algumas exceções, como apresentado a seguir:

Gráfico 1: Precipitação em São Domingos e Posse - 2012

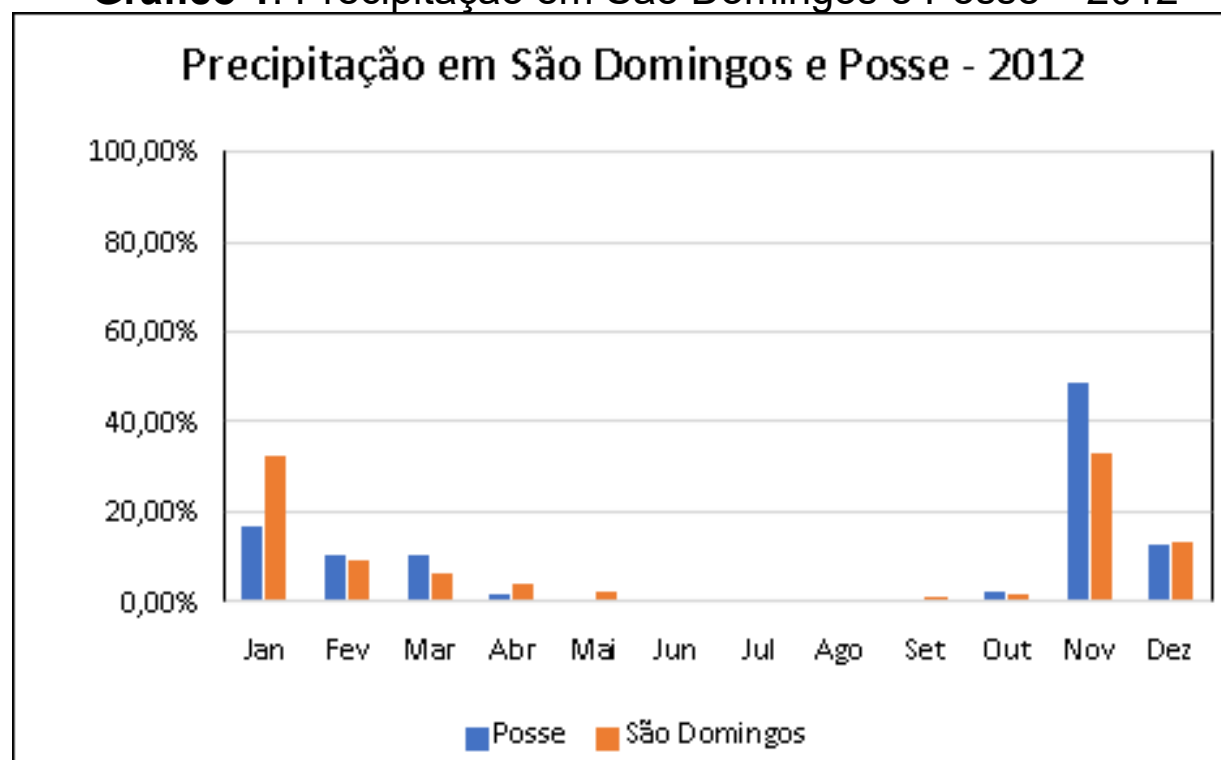

Fonte: Elaboração de Barros (2019).

Em 2012, a análise das precipitações, principalmente em São Domingos-GO, nos mostra que houve um período de seca que se estendeu mais do que nos outros anos, bem como a porcentagem de precipitação foi baixa, com exceção do mês de novembro, em Posse, e de janeiro, em São Domingos, que apresentaram quantidade bem superior aos meses do ano de 2012 de chuva. 
Gráfico 2: Precipitação em São Domingos e Posse - 2015

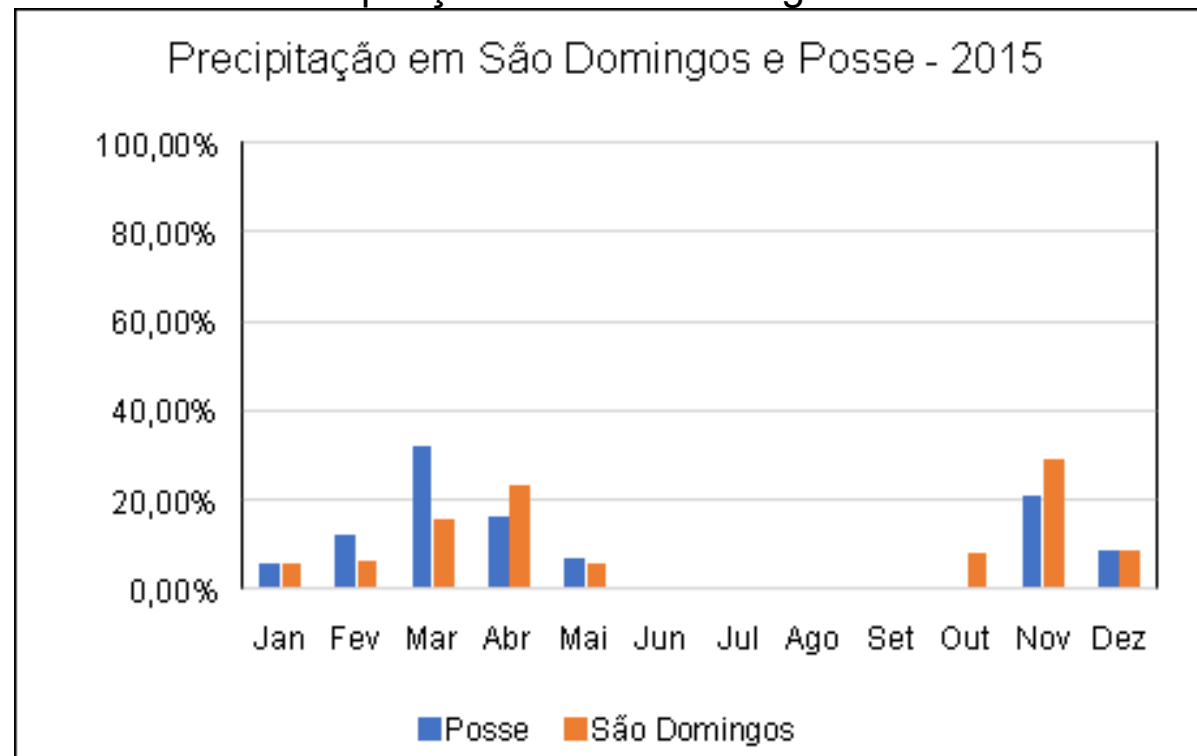

Fonte: Elaboração de Barros (2019).

Outro ano que nos chama a atenção para meses extremante secos, tanto medidos pela estação de Posse quanto pela de São Domingos, bem como para certa regularidade nos meses chuvosos, é 2015. Esse ano foi marcado por nenhuma chuva, de acordo com as estações meteorológicas, bem como um período regular durante o período chuvoso.

Dessa forma, pode-se afirmar que, dos 10 anos analisados, foram encontrados 2 anos de exceções: um com período seco maior que os demais anos e outro com meses mais chuvosos. Retirando esses dois anos apresentados anteriormente, podemos determinar que os períodos secos e chuvosos não variam muito. A partir daí, podemos começar a estabelecer períodos para melhor aproveitar os atrativos naturais como: fitofisionomias, veredas, cavernas entre outros.

O turismo paisagístico pode ser praticado a qualquer período do ano, vez que cada turista busca a fruição da paisagem conforme sua necessidade. Abaixo mostram-se alguns exemplos da diversidade paisagística e do que o turista pode consumir. 
Quadro 2: Atrativos naturais de São Domingos

\begin{tabular}{|c|c|}
\hline & $\begin{array}{l}\text { O Cerrado Rupestre é um subtipo de vegetação } \\
\text { arbóreo-arbustiva que ocorre em ambientes } \\
\text { rupestres (rochosos). Possui cobertura arbórea } \\
\text { variável de } 5 \% \text { a } 20 \% \text {, com altura média de dois a } \\
\text { quatro metros, e camada arbustivo-herbácea } \\
\text { destacada. Pode ocorrer em trechos contínuos, mas } \\
\text { geralmente aparece em mosaicos, incluído em } \\
\text { outros tipos de vegetação. Embora possua estrutura } \\
\text { semelhante ao Cerrado Ralo e até ao Típico, seu } \\
\text { substrato comporta uma vegetação sobre pouco solo } \\
\text { entre afloramentos de rocha. Os solos desta } \\
\text { paisagem são originados da decomposição de } \\
\text { arenitos e quartzitos, pobres em nutrientes, ácidos e } \\
\text { com baixos teores de matéria orgânica (Neossolos } \\
\text { Litólicos). }\end{array}$ \\
\hline 5 & $\begin{array}{l}\text { A ocorrência da Vereda condiciona-se ao } \\
\text { afloramento do reservatório subterrâneo de água } \\
\text { (lençol freático), decorrente de camadas de } \\
\text { permeabilidade diferentes em áreas de deposição de } \\
\text { sedimentos do período Cretáceo (período geológico } \\
\text { que se estendeu entre } 141 \text { milhões e } 65 \text { milhões de } \\
\text { anos antes do período presente) e Triássico (período } \\
\text { compreendido entre } 251 \text { milhões e } 199 \text { milhões e } \\
600 \text { mil anos atrás, aproximadamente). As veredas } \\
\text { exercem papel fundamental na distribuição dos rios e } \\
\text { seus afluentes, na manutenção da fauna do Cerrado, } \\
\text { funcionando como local de pouso para a fauna de } \\
\text { aves, atuando como refúgio, abrigo, fonte de } \\
\text { alimento e local de reprodução para a fauna terrestre } \\
\text { e aquática. Apesar dessa importância, as Veredas } \\
\text { têm sido progressivamente pressionadas em várias } \\
\text { localidades do bioma Cerrado devido às ações } \\
\text { agrícolas e pastoris. Além disso, têm sido } \\
\text { descaracterizadas pela construção de pequenas } \\
\text { barragens e açudes, por estradas, pela agricultura, } \\
\text { pela pecuária e até mesmo por queimadas } \\
\text { excessivas. O simples pisoteio do gado pode causar } \\
\text { processos erosivos e compactação do solo, que } \\
\text { afetam a taxa de infiltração de água que vai } \\
\text { alimentar os reservatórios subterrâneos. }\end{array}$ \\
\hline
\end{tabular}

Fonte: Disponível em: https://www.embrapa.br/cerrados/colecao-
entomologica/bioma-cerrado.

Outo segmento do turismo muito praticado em São Domingos-GO é o Ecoturismo, entretanto, não se seguem, no município, os critérios adotados pelo Beni (2001) em relação à regulamentação e à proteção legal da localidade. Está-se falando do Parque Estadual Terra Ronca (PETeR). O parque não possui plano de manejo e tampouco acompanhamento dos órgãos responsáveis pela conservação. O PETeR é um dos maiores conjuntos de cavernas da América Latina, possuiu um relevo cársico com inúmeras geoformas, ${ }^{4}$ mas há um conflito de uso no parque e na principal caverna, a que tem maior fluxo de turista, conforme guias locais. Há um altar para o Santo Bom Jesus da Lapa, onde é feita, todo ano, uma peregrinação, porém, esse altar fica dentro da caverna Terra Ronca I e os fiéis, por acreditarem

${ }^{4}$ Geoformas são as formas de relevo, feições geomorfológicas, como, por exemplo, estalactites. 
que a água que cai perto do altar possui elementos milagrosos, tocam nas estalagmites, prejudicando sua sedimentação.

Apesar do não controle, as cavernas se enquadram no segmento do Ecoturismo. Ainda, essas geoformas não podem ser visitadas, por exemplo, em período chuvosos, uma vez que não se consegue prever o volume de água que pode ser represada na caverna, o que acarreta sérios riscos aos visitantes. Por esse motivo, aconselha-se a visitação no período de transição, por exemplo, em abril, maio e outubro. Nos outros meses a visitação não está fechada aos turistas, mas, nos meses chuvosos, a decisão de entrar nas cavernas é dos guias de turismo. No período seco, a paisagem no interior da caverna não é tão exuberante.

\section{Quadro 3: Caverna Terra Ronca I}

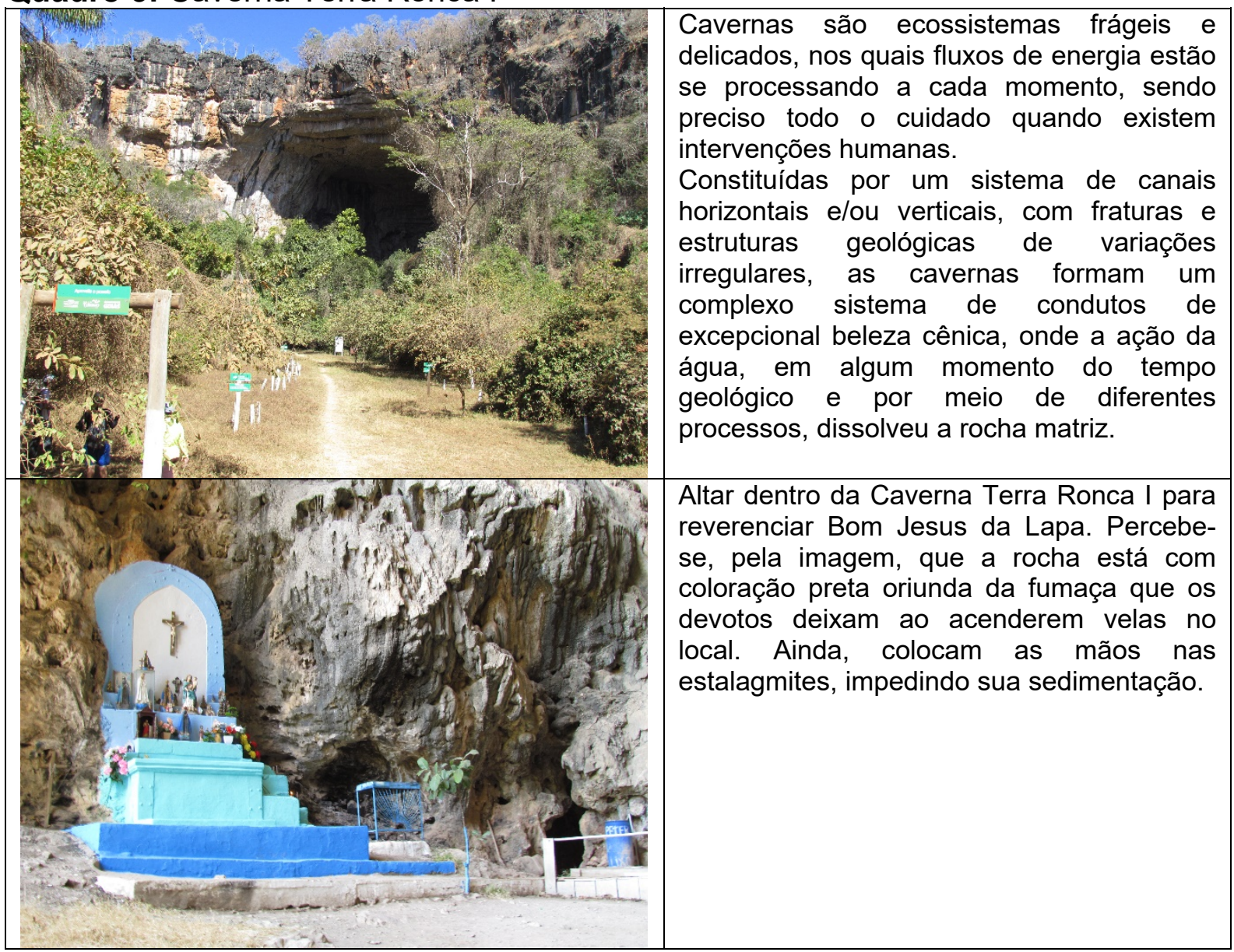

Fonte: Disponível em: http://www.icmbio.gov.br/cecav/cavidades-naturaissubterraneas.html. 


\section{CONCLUSÃO}

É certo afirmar que o Turismo é um dos maiores segmentos econômicos do globo, pois envolve diversas esferas e movimenta trilhões de dólares por meio de um fluxo intenso de pessoas. Essa atividade vem se desenvolvendo cada vez mais a partir da Revolução Industrial e, como estamos vivendo no período técnico-científicoinformacional (SANTOS, 1996), os turistas têm acesso a pesquisa sobre os lugares que lhes interessam.

Assim como em quase todo processo produtivo, o turismo também passou por um processo de segmentação. Por ser um processo socioeconômico, é difícil equalizar os lucros com a sustentabilidade (tanto social quanto ambiental), haja vista o desejo de se ter um lucro a pequeno e médio prazo.

Um segmento que vem crescente cada vez mais, como aponta a Organização Internacional do Turismo (UNTWO, 2018), é o ligado à natureza. Isso porque nossa sociedade urbana e industrial está cansada do dia a dia de trabalho, das exigências institucionais que agora ultrapassam as oito horas diárias devido à tecnologia. Diante disso, esse segmento cresce e, por conseguinte, acaba por exigir mais estudos relativos aos elementos ligados a ele.

Também é certo que por mais estudos que haja acerca desse segmento, capazes de orientar o turista sobre o melhor período de visitação aos destinos escolhidos, há poucos estudos que apresentem essa discussão. Vários elementos estão ligados ao turismo de natureza e outros segmentos que a exploram e/ou a consomem, entre eles clima, geomorfologia, fitofisionomias, geologia etc., todos abordados pela Geografia, que tem sido uma aliada para dar robustez aos debates do turismo, tanto do ponto de vista social como ambiental.

Este trabalho apresentou o clima como principal elemento a ser pesquisado antes de se escolher o atrativo a ser consumido. Entretanto, vale ressaltar que a procura de um destino turístico tem vários incentivos, como marketing, imaginário, estórias de amigos, entre outros. Estudos como este tem como objetivo auxiliar o turista a vislumbrar as atividades que eles podem praticar no núcleo receptor escolhido.

Foi escolhido o município de São Domingos-GO como exemplo desta discussão, uma vez que esse município está localizado no bioma Cerrado, com diversas fitofisionomias que podem atrair um número maior de turistas ligados ao turismo de natureza. Esse segmento também é diversificado e consumido como apresentado no respectivo artigo. Entre as formas do Cerrado apresentadas em São Domingos, temos: Cerrado Rupestre, Cerradão, Veredas, Mata Galeria, Morro Residual, Cavernas etc. Cada um desses elementos está ligado ao segmento do turismo de natureza, mas há especificações teóricas para cada um dos elementos apresentados anteriormente.

Assim, pode-se afirmar que São Domingos-GO é um destino que possui muitos elementos a serem visitados. O dilema é saber como consumir essas paisagens e, nesse sentido, o primeiro passo é saber sobre o clima da região, fator de suma importância para a escolha dos atrativos que serão visitados.

\section{REFERÊNCIAS BIBLIOGRÁFICAS}


ALMEIDA, Marcelo Vilela de. Matriz de avaliação do potencial turístico de localidades receptoras. 2006. Tese (Doutorado) - Universidade de São Paulo, São Paulo, 2006.

ARANHA, Raphael de Carvalho; GUERRA, Antonio José Teixeira (Org.). Geografia aplicada ao Turismo. São Paulo: Oficina de Textos, 2014.

BARBIÉRE, E. B. O fator climático nos sistemas territoriais de recreação. Revista Brasileira de Geografia, Rio de Janeiro, ano 43, n. 2, p. 145-266, abr./jun. 1981.

BARRETO, M. Manual de iniciação ao estudo do turismo. 13. ed. Campinas, SP: Ed. Papirus, 2003.

BARREIRA, Celene Cunha Monteiro Antunes. Vão do Paranã: estruturação de uma região. Brasília: Ministério da Integração Nacional; Goiânia: UFG, 2002.

BARROS, J. R.; ZAVATTINI, J. A. Bases conceituais em climatologia geográfica. Mercator - Revista de Geografia da UFC, ano 8, n. 16, p. 255-261, 2009.

BENI, Mário Carlos. Análise estrutural do turismo. 5. ed. São Paulo: Ed. Senac, 2001.

BESANCENOT, J.-P. Climate et tourisme. Paris: Masson, 1990. (Collection Géographie).

CECAV - Centro Nacional de Pesquisa e Conservação de Cavernas - CECAV: http://www.icmbio.gov.br/cecav/cavidades-naturais-subterraneas.html: Acesso em: 18 out. 2019.

CHAVEZ, Eros Salinas; PÉREZ, Norman Medina. Los productos turísticos, pilares de la comercialización: dos ejemplos del centro histórico de la Habana, Cuba.

Universidade de La Habana, Cuba, v. 18, p. 227-242, 2009

FERREIRA de Aguiar Junior, Paulo Roberto. Avaliação da Potencialidade dos Atrativos Ecoturísticos do Município de São Domingos, Goiás. Dissertação (Mestrado) - Universidade Federal de Goiás, Instituto de Estudos Socioambientais (lesa), Programa de Pós Graduação em Geografia, Goiânia, 2019.

GUERRA, A. J. T.; MARÇAL, M. dos S. Geomorfologia ambiental. 6. ed. Rio de Janeiro: Ed. Bertrand, 2014.

IBGE - Instituto Brasileiro de Geografia e Estatística. Brasil/Goiás/São Domingos. Disponível em: https://cidades.ibge.gov.br/brasil/go/sao-domingos/panorama. Acesso em: 15 maio. 2018.

KNAFOU, R. et al. Une approche géographique du tourisme. Espaces du tourisme, p. 193-204, mar. 1997.

NIMER, Edmon. Climatologia do Brasil. Rio de Janeiro: IBGE, Departamento de Recursos Naturais e Estudos Ambientais, 1979. 
OLIVEIRA, Ivanilton José de. O Povo do Cerrado: Relações entre população e ambiente no estado de Goiás. Revista GEOUSP - Espaço e Tempo, São Paulo, n.29, pp.124-136, 2008.

SANTOS, Milton. Natureza do espaço. São Paulo: Nobel, 1996. p. 61-110

SCOTT, D.; MCBOYLE, G. Using a 'tourism climate index' to examine the implications of climate change for climate as a tourism resource. Jan. 2001. Disponível em:

https://www.researchgate.net/publication/238102783 Using a 'tourism climate index' to examine the implications of climate change for climate as a tourism re source.

SORRE, M. Les Fondements de la Géograhie Humaine. Tome Premier: Les fondaments biologiques. Paris: Armand. Colin, 1951.

UNWTO - World Tourism Organization. UNWTO - Annual Report 2015. Disponível em:

$<$ http://www.dadosefatos.turismo.gov.br/images/pdf/estatisticas_indicadores/UNTWO_Ann ual_report_2015.pdf>. Acesso em: 18 ago. 2015.

VASQUES, Hérika Silva 0 regime pluviométrico, o ritmo e as excepcionalidades das precipitações em Jataí - GO. Dissertação (Mestrado) - Universidade Federal de Goiás (lesa), Programa de Pós-Graduação em Geografia, Goiânia, Goiás, 2017. 